Check for updates

Cite this: RSC Adv., 2019, 9, 9737

\title{
Synthesis and gas transport properties of polyamide membranes containing PDMS groups
}

\begin{abstract}
Liexiang Ren (D)* and Jin Liu
A series of gas-separation polyamide-poly(dimethylsiloxane) (PA-PDMS) membranes containing PDMS groups were synthesized through the polycondensation reaction. The structural characteristics of polymers were evaluated by ${ }^{1} \mathrm{H}-\mathrm{NMR}$ spectroscopy (NMR), Fourier-transform infrared spectroscopy (FTIR) and UV-vis absorption spectroscopy. The permeability and selectivity behavior was studied at different temperatures $\left(25-55^{\circ} \mathrm{C}\right.$ ) and pressures (1.0-3.0 atm), using various gases, such as $\mathrm{H}_{2}, \mathrm{O}_{2}, \mathrm{CO}_{2}$, $\mathrm{CH}_{4}$, and $\mathrm{N}_{2}$. The effect of chemical structure, PDMS content, operating pressure and temperature on gas permeability was explored and discussed. Gas-permeation measurements showed that polyamides containing PDMS groups exhibited different separation performance. The PA-PDMS-20 membrane with $20 \mathrm{wt} \%$ PDMS exhibited the highest selectivity $\left(\mathrm{CO}_{2} / \mathrm{N}_{2}=41.84\right.$ and $\left.\mathrm{O}_{2} / \mathrm{N}_{2}=7.01\right)$ at $35^{\circ} \mathrm{C}$ and 3.0 atm while $\mathrm{CO}_{2}$ and $\mathrm{O}_{2}$ permeability was 29.29 barrer and 4.91 barrer, respectively.
\end{abstract}

Received 25th December 2018

Accepted 13th March 2019

DOI: $10.1039 / \mathrm{c} 8 \mathrm{ra10550b}$

rsc.li/rsc-advances

a high free volume for gas transport. A very high permeability is hence expected for membranes prepared from PDMS. In order to enhance gas permeability, several approaches, including crosslinking or grafting of PDMS onto the polymer have been successfully applied. For instance, Yang et al. synthesized and characterized a series of SBS-PDMS crosslinked membranes. ${ }^{17}$ The $\mathrm{CH}_{4}$ permeability of SBS-c-PDMS-co-PMHS-70 sample has notably enhanced to 443.6 barrer at $25{ }^{\circ} \mathrm{C}$ and 1 bar as compared to 37.6 barrer over the pure SBS membrane. Hyelim et al. studied the crosslinked polyimide polydimethylsiloxane (PI-PDMS) copolymer membranes. These crosslinked copolymers exhibited excellent thermochemical stability and $\mathrm{CO}_{2}$ separation performance $\left(\mathrm{PCO}_{2}\right.$ of 799 barrer and $\mathrm{CO}_{2} / \mathrm{N}_{2}$ permselectivity of 15.7$).^{18}$

Based on the above design considerations, a series of PAs containing PDMS group were synthesized in the present work via polycondensation towards enhancing gas permeability. After FTIR, ${ }^{1} \mathrm{H}$ NMR, and UV-visible absorption spectra characterizations, the single-gas $\left(\mathrm{H}_{2}, \mathrm{O}_{2}, \mathrm{CO}_{2}, \mathrm{CH}_{4}\right.$, and $\left.\mathrm{N}_{2}\right)$ permeation properties of the membranes were evaluated at $25{ }^{\circ} \mathrm{C}$ and $1.0 \mathrm{~atm}$. In addition, the effect of PDMS content on single-gas separation properties of membranes was extensively discussed. The gas permeability of the optimum PA-PDMS-20 membrane was further explored in a wide temperature (25-55 ${ }^{\circ} \mathrm{C}$ ) and pressure (1.0-3.0 atm) range.

\section{Experimental}

\subsection{Materials}

All chemicals and reagents were used without further purification. 4,4'-Oxybis (benzoic acid) (OBA, 98\%) were purchased from Meryer Chemical Technology Co., Ltd., China. 
Poly(dimethylsiloxane)bis(aminokyl) terminated (PDMS, $M_{\mathrm{w}}=$ $2000 \mathrm{~g} \mathrm{~mol}^{-1}$ ) was obtained from Aladdin (China). 4,4'-(9-Fluorenylidene)dianiline (9FDA) was synthesized according to the reported procedure. ${ }^{19} \mathrm{~N}, \mathrm{~N}$-Dimethylformamide (DMF), $\mathrm{N}, \mathrm{N}$ dimethylacetamide (DMAc), triphenyl phosphite (TPP, 99\%), pyridine (Py, 99\%) and calcium chloride were supplied by Tianjin Reagent Co., Ltd., China. Cylinders of $\mathrm{CO}_{2}, \mathrm{CH}_{4}$ and $\mathrm{N}_{2}$ gases (99.9\%) were purchased from Gas Production Plant, Taiyuan, China.

\subsection{Synthesis of PA-PDMS copolymers}

Polyamide-poly(dimethylsiloxane)s containing PDMS groups (PA-PDMS- $x$, $x$ : weight content (wt $\%$ ) of PDMS) are successfully synthesized via condensation copolymerization as shown in Scheme 1. A typical procedure for the synthesis of PA-PDMS-20 has as follows: a mixture of OBA $(0.294 \mathrm{~g}, 1.14 \mathrm{mmol})$, 9FDA (0.368 g, $1.05 \mathrm{mmol}$ ), PDMS (0.166 g, $0.09 \mathrm{mmol}), 1.4 \mathrm{~mL}$ of Py, TPP (1.4 mL, $5.34 \mathrm{mmol}), 5 \mathrm{~mL}$ of DMAc and calcium chloride $(0.36 \mathrm{~g})$ were taken in a $100 \mathrm{~mL}$ round-bottom flask equipped with a reflux condenser and a nitrogen inlet. The reaction mixture was heated at $120{ }^{\circ} \mathrm{C}$ for $36 \mathrm{~h}$ under continuous stirring. Afterwards, it was poured slowly into $150 \mathrm{~mL}$ methanol to obtain the crude products. Finally, the crude products were filtered and washed several times with methanol followed by hot and cold deionized water to remove the adsorbed solvent and residual $\mathrm{CaCl}_{2}$. The final products were dried in a vacuum oven at $60{ }^{\circ} \mathrm{C}$ for $24 \mathrm{~h}$. A series of PA-PDMS- $x$ (as show in Scheme 1) were successfully synthesized using the same procedure as described for synthesis of PA-PDMS-10. The reaction conditions and properties of copolymer are listed in Table 1.

\subsection{Preparation of PA-PDMS copolymer membranes}

PA-PDMS- $x(0.2 \mathrm{~g})$ was dissolved in DMAc $(25 \mathrm{~mL})$ to obtain an $8 \%$ solution. The solution was placed on a flat glass plate and dried in oven at $80{ }^{\circ} \mathrm{C}$ for $24 \mathrm{~h}$ to obtain a thin (50-70 $\mu \mathrm{m}$ thick), transparent and tough membrane.
Table 1 Yield, inherent viscosity, density and fractional free volume (FFV) of PA-PDMS copolymers

\begin{tabular}{llllllll}
\hline & \multicolumn{2}{c}{ Monomer feed $(\mathrm{g})$} & & & & \\
\cline { 2 - 6 } Polymer & OBA & 9FDA & PDMS & $\begin{array}{l}\eta_{\text {inh }} \\
(\%)\end{array}$ & $\begin{array}{l}\rho \\
\left(\mathrm{dL} \mathrm{g}^{-1}\right)\end{array}$ & $\left(\mathrm{g} \mathrm{mL}^{-1}\right)$ & FFV \\
\hline PA-PDMS-5 & 0.294 & 0.393 & 0.036 & 96.3 & 4.694 & 1.114 & 0.212 \\
PA-PDMS-10 & 0.294 & 0.386 & 0.076 & 95.5 & 4.332 & 1.119 & 0.207 \\
PA-PDMS-15 & 0.294 & 0.378 & 0.118 & 97.1 & 4.018 & 1.125 & 0.203 \\
PA-PDMS-20 & 0.294 & 0.368 & 0.166 & 95.8 & 4.676 & 1.130 & 0.197 \\
& & & & & & & \\
\hline
\end{tabular}

\subsection{Characterization}

FTIR measurements were recorded on a Bruker TENSOR II FTIR spectrometer (Germany) in the range of 4000-400 $\mathrm{cm}^{-1} \cdot{ }^{1} \mathrm{H} \mathrm{NMR}$ spectra were performed on a $400 \mathrm{MHz}$ Bruker AVANCE IIITM NMR spectrometer (Germany) using DMSO- $d_{6}$ as solvent at room temperature. The solubility of each polymer was tested by dissolving $20 \mathrm{mg}$ of polymer in $1 \mathrm{~mL}$ of different solvents, followed by continuous stirring for $24 \mathrm{~h}$ at room temperature. Inherent viscosities $\left(\eta_{\text {inh }}\right)$ were determined using an Ubbelohde viscometer (JC522-1835, China) at $30 \pm 0.1{ }^{\circ} \mathrm{C}$ with NMP as solvent at a concentration of $0.5 \mathrm{~g} \mathrm{dL}^{-1}$. UV-visible absorption spectra of the polymers were recorded on a Metash UV-8000A spectrometer (China) using DMF as solvent in a wavelength range of 200$600 \mathrm{~nm}$. The density $(\rho)$ of the PA-PDMS copolymers was estimated in a density gradient column (Techne Corp) based on aqueous calcium nitrate solutions, between 1.0 and $1.3\left(\mathrm{~g} \mathrm{~mL}^{-1}\right)$ at $25{ }^{\circ} \mathrm{C}$. The fractional free volume (FFV) was calculated by the following eqn (1): ${ }^{20}$

$$
\mathrm{FFV}=\frac{V_{\mathrm{sp}}-1.3 V_{\mathrm{w}}}{V_{\mathrm{sp}}}
$$

where $V_{\mathrm{sp}}$ is the specific volume $\left(V_{\mathrm{sp}}=1 / \rho\right)$ and $V_{\mathrm{w}}$ is the van der Waals volume determined using Bondi's group contribution method. ${ }^{15}$ In the case of copolymers, $V_{\mathrm{w}}$ was estimated by $V_{\mathrm{w}}=$ $x_{1} V_{\mathrm{w}_{1}}+x_{2} V_{\mathrm{w}_{2}}$, where $x_{1}$ and $x_{2}$ are the molar fractions of the<smiles>CC(C)(C)Nc1ccc(C2(c3ccc(NC(=O)c4cccc(Oc5cccc(C(=O)NCCCO[Si](C)(C)OCCCCNC(=O)c6cccc(Oc7cccc(C(C)(C)C)c7)c6)c5)c4)cc3)c3ccccc3-c3ccccc32)cc1</smiles>

Scheme 1 Synthesis of PA-PDMS copolymers. 


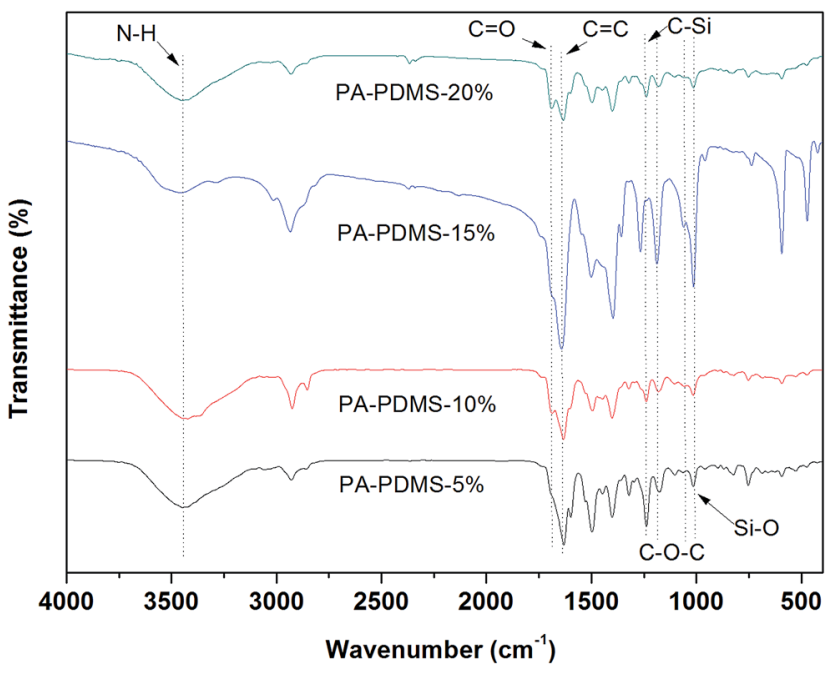

Fig. 1 FTIR spectra of PA-PDMS copolymers.

polyamide segments and PPG segments, respectively; $V_{\mathrm{w}_{1}}$ and $V_{\mathrm{w}_{2}}$ are the van der Waals volumes for the two segments, respectively. Mechanical properties of the membranes were measured using a Shimadzu Autograph AGS-X $500 \mathrm{~N}$ tensile testing instrument with a strain rate of $5 \% \mathrm{~min}^{-1}$ at room temperature. The rectangular specimens were fabricated with an initial width of $8 \mathrm{~mm}$, gauge length of $30 \mathrm{~mm}$ and thickness of 30-50 $\mathrm{lm}$.

\subsection{Gas permeability measurements}

Gas permeability of the membranes was performed using a gas permeability device (VAC-V2, Labthink Instruments Company, China). Gas permeation properties of the membranes were determined using five gases, i.e. $\mathrm{CO}_{2}, \mathrm{CH}_{4}$ and $\mathrm{N}_{2}$, at a feed pressure of $1.0 \mathrm{~atm}$ and different temperatures $\left(25-55{ }^{\circ} \mathrm{C}\right)$. The permeability $(P)$ of each gas was calculated by the eqn $(2):{ }^{21}$

$$
P=\frac{1}{76} \frac{273.15}{T} \frac{V}{A} \frac{1}{\Delta P} \frac{\mathrm{d} p}{\mathrm{~d} t}
$$

where $P$ is the gas permeability (barrer) $\left(1\right.$ barrer $=1 \times 10^{-10}$ $\mathrm{cm}^{3}$ (STP) $\left.\mathrm{cm}\left(\mathrm{cm}^{-2} \mathrm{~s}^{-1} \mathrm{cmHg}^{-1}\right)\right) ; \Delta P$ is the trans-membrane pressure difference $(\mathrm{Pa}) ; A$ is the effective membrane area $\left(\mathrm{cm}^{2}\right), T$ is the operating temperature (K); $l$ is the membrane thickness $(\mathrm{cm}) ; V$ is the downstream volume $\left(\mathrm{cm}^{3}\right)$ and $\mathrm{d} p / \mathrm{d} t$ is the rate of the pressure rise under the steady state.

Lag method using the following equation:

$$
D=L^{2} / 6 \theta
$$

where $D$ is the diffusion coefficient $\left(10^{8} \mathrm{~cm}^{2} \mathrm{~s}^{-1}\right), L$ is the membrane thickness, and $\theta$ is the time lag, which is given by the intercept of the asymptotic line of time-pressure curve to the time axis.

The $S$ value was calculated by using equation:

$$
S=P / D
$$

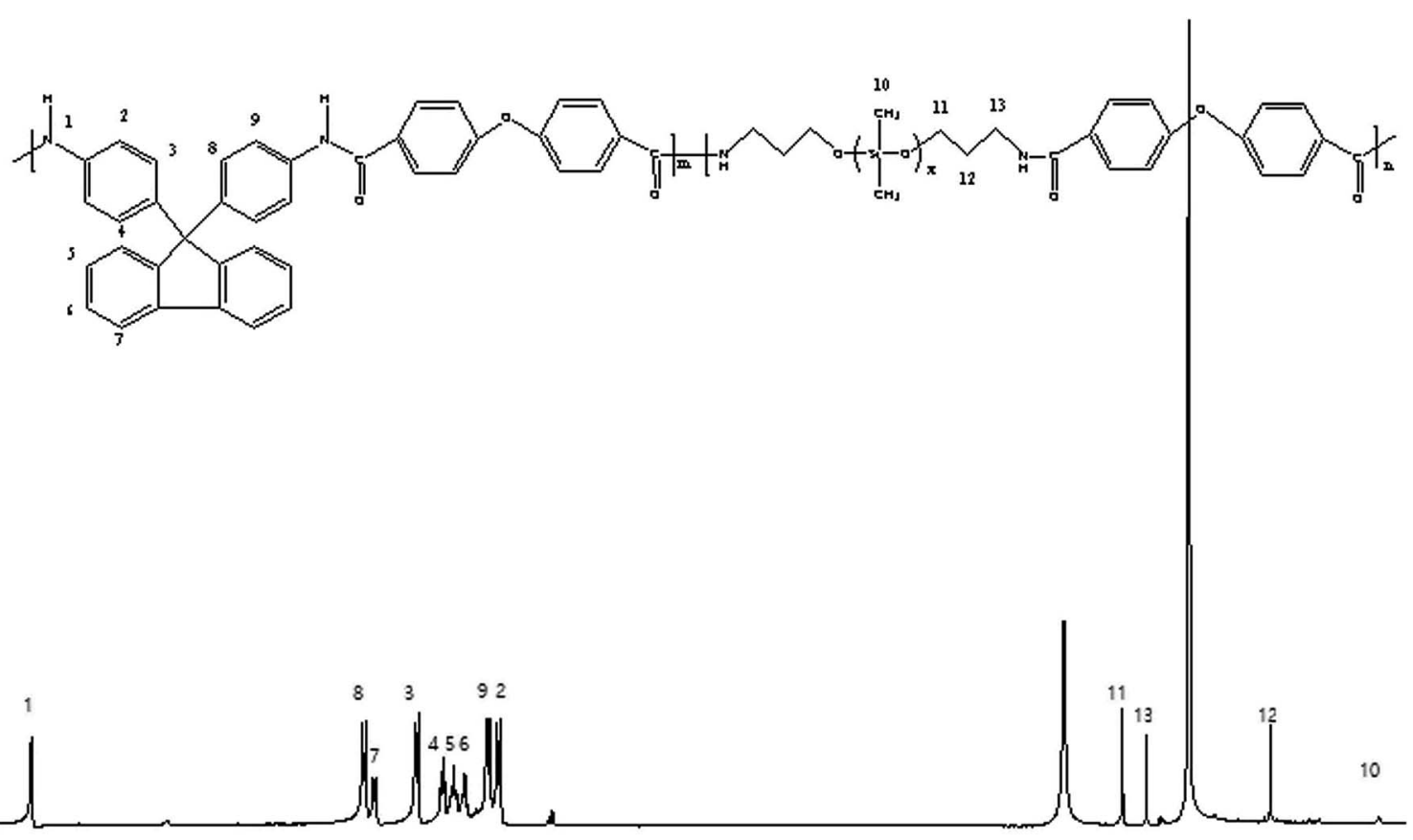

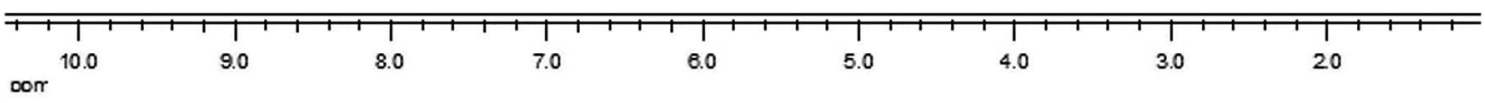

Fig. $2{ }^{1} \mathrm{H}$ NMR spectra of PA-PDMS-10. 
Table 2 Mechanical properties of PA-PDMS-x membranes

\begin{tabular}{lll}
\hline Polymer & Tensile strength (MPa) & Elongation at break (\%) \\
\hline PA & 22 & 36 \\
PA-PDMS-5 & 23 & 30 \\
PA-PDMS-10 & 21 & 44 \\
PA-PDMS-15 & 25 & 26 \\
PA-PDMS-20 & 18 & 51 \\
\hline
\end{tabular}

where $S$ is the solubility coefficient $\left(10^{3} \mathrm{~cm}^{3} \mathrm{STP} \mathrm{cm}^{-3} \mathrm{cmHg}^{-1}\right)$.

The ideal selectivity $(\alpha)$ of one penetrant (A) over another (B) is given by:

$$
\alpha_{\mathrm{A} / \mathrm{B}}=\frac{P_{\mathrm{A}}}{P_{\mathrm{B}}}
$$

\section{Results and discussion}

\subsection{Synthesis and characterization of PA-PDMS copolymers}

The PA-PDMS copolymers were synthesized by polycondensation reaction as illustrated in Scheme 1 . The density and FFV values of polymers were summarized in Table 1 . The density values of PAPDMS copolymers were in the range of 1.114-1.130 $\mathrm{g} \mathrm{mL}^{-1}$, while their FFV values varied from 0.197 to 0.212 . As expected, the FFV values of the PA-PDMS copolymers gradually decreased with the increase of PDMS content, due to the cracks of polymer chains filled with the flexible PDMS soft segments.

The chemical structure of the PA-PDMS- $x$ samples was confirmed based on the FTIR spectra in Fig. 1. The bands at 1635,1184 , and $1163 \mathrm{~cm}^{-1}$ belong to aromatic $\mathrm{C}=\mathrm{C}$ stretching vibration, ${ }^{22} \mathrm{C}-\mathrm{O}-\mathrm{C}$ stretching vibration of OBA, respectively. On the other hand, the swing at $1251 \mathrm{~cm}^{-1}$ and $1009 \mathrm{~cm}^{-1}$ can be attributed to $-\mathrm{Si}-\mathrm{O}-\mathrm{Si}-$ and $-\mathrm{Si}\left(\mathrm{CH}_{3}\right)_{2}-\mathrm{O}-$ in PDMS. The $\mathrm{N}-\mathrm{H}$ and $\mathrm{C}=\mathrm{O}$ stretching vibrations from amide groups were observed approximately at 3442 and $1668 \mathrm{~cm}^{-1}$, respectively.

The chemical structure of the PA-PDMS-5 was further examined by ${ }^{1} \mathrm{H}$ NMR with DMSO- $d_{6}$ as the solvent. The ${ }^{1} \mathrm{H}$ NMR spectra of PA-PDMS-5 sample is shown in Fig. 2. A group of peaks at 7.0-8.1 ppm are due to the aromatic protons of benzene ring. ${ }^{23}$ The peaks at $1.2 \mathrm{ppm}$ are assigned to $-\mathrm{CH}_{3}^{*}$ groups protons of PDMS. ${ }^{24}$ In addition, the peak at $10.2 \mathrm{ppm}$ is originated by amide group proton, indicating the successful synthesis of PA-PDMS copolymers. The mechanical properties of the membranes were measured at room temperature (Table 2 ). The membranes samples of PA-PDMS- $x$ showed higher tensile strength (18-23 MPa) and lower strain (30-51\%). These data indicate these membranes are strong and tough enough to be applied as membrane for gas separation.

\subsection{UV-vis absorption analysis}

UV-vis absorption spectrum is a useful method to analyze molecular interactions. ${ }^{25}$ UV-vis absorption bands of PA-PDMS copolymers were performed in DMF solvent at room temperature and the results are presented in Fig. 3. As shown in Fig. 3, polymers exhibited similar absorption bands between 268 and $340 \mathrm{~nm}$, indicating that the center of absorption bands is related to intramolecular and intermolecular charge-transfer interactions. Furthermore, the maximum absorption band $\left(\lambda_{\text {max }}\right)$ of PA-PDMS copolymers tend to red-shifted towards higher wavelength with the increase in PDMS content. The short absorption band is generally found in the intramolecular chargetransfer complexes, whereas the intermolecular charge-transfer occurs in the long absorption band. ${ }^{26}$ The following order, in relation to $\lambda_{\max }$ values, was obtained: PA-PDMS-5 $<$ PA-PDMS-10 $<$ PA-PDMS-15 < PA-PDMS-20. Therefore, the order of the intermolecular interaction strength of polymers is PA-PDMS-5 < PAPDMS-10 < PA-PDMS-15 < PA-PDMS-20. The strong intermolecular interaction resulted in the reduction of the distance between

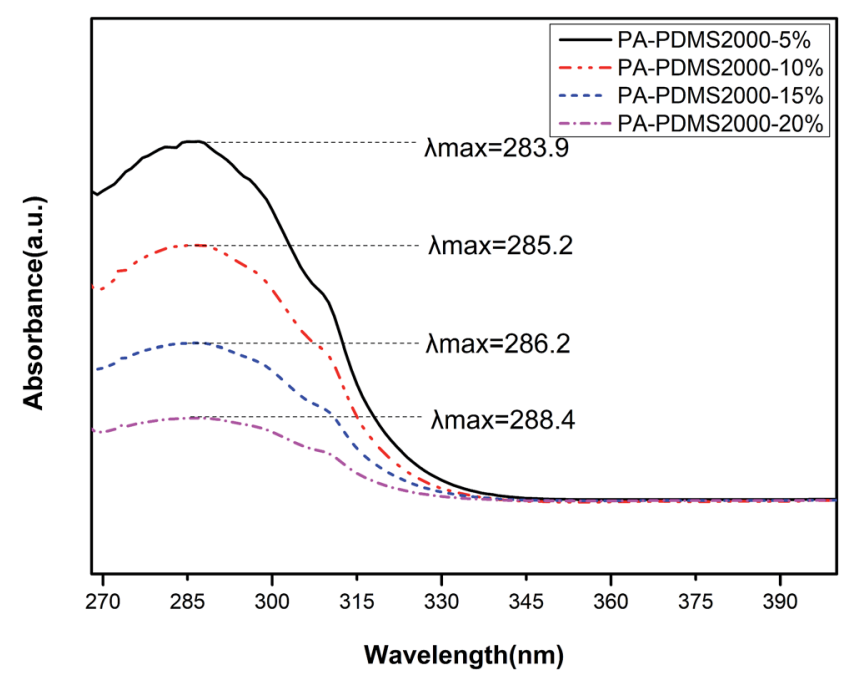

Fig. 3 UV-vis absorption bands of PA-PDMS copolymers.

Table 3 Gas permeability of PA-PDMS copolymer membranes at $25^{\circ} \mathrm{C}$ and $1.0 \mathrm{~atm}^{a}$

\begin{tabular}{|c|c|c|c|c|c|}
\hline Polymer & $P\left(\mathrm{H}_{2}\right)$ & $P\left(\mathrm{CO}_{2}\right)$ & $P\left(\mathrm{O}_{2}\right)$ & $P\left(\mathrm{CH}_{4}\right)$ & $P\left(\mathrm{~N}_{2}\right)$ \\
\hline PA & $8.09 \pm 0.19$ & $6.58 \pm 0.11$ & $1.31 \pm 0.03$ & $0.32 \pm 0.05$ & $0.26 \pm 0.01$ \\
\hline PA-PDMS-5 & $10.53 \pm 0.38$ & $8.87 \pm 0.42$ & $1.55 \pm 0.11$ & $0.37 \pm 0.08$ & $0.29 \pm 0.01$ \\
\hline PA-PDMS-10 & $13.92 \pm 0.21$ & $11.65 \pm 0.51$ & $2.14 \pm 0.09$ & $0.45 \pm 0.03$ & $0.37 \pm 0.05$ \\
\hline PA-PDMS-15 & $17.67 \pm 0.59$ & $14.31 \pm 0.72$ & $2.61 \pm 0.06$ & $0.53 \pm 0.01$ & $0.43 \pm 0.02$ \\
\hline PA-PDMS-20 & $22.14 \pm 0.93$ & $18.02 \pm 0.86$ & $3.19 \pm 0.15$ & $0.66 \pm 0.12$ & $0.51 \pm 0.09$ \\
\hline
\end{tabular}

${ }^{a}$ Gas permeability $(P)$ in barrer. 1 barrer $=10^{-10} \mathrm{~cm}^{3}(\mathrm{STP}) \mathrm{cm}^{-1} \mathrm{~cm}^{-2} \mathrm{~s}^{-1} \mathrm{cmHg}^{-1}$. 
Table 4 Selectivity of PA-PDMS copolymer membranes at $25^{\circ} \mathrm{C}$ and $1.0 \mathrm{~atm}$

\begin{tabular}{|c|c|c|c|c|c|}
\hline Polymer & $\alpha\left(\mathrm{H}_{2} / \mathrm{N}_{2}\right)$ & $\alpha\left(\mathrm{H}_{2} / \mathrm{CH}_{4}\right)$ & $\alpha\left(\mathrm{CO}_{2} / \mathrm{N}_{2}\right)$ & $\alpha\left(\mathrm{CO}_{2} / \mathrm{CH}_{4}\right)$ & $\alpha\left(\mathrm{O}_{2} / \mathrm{N}_{2}\right)$ \\
\hline PA & $31.16 \pm 1.91$ & $25.28 \pm 1.02$ & $25.31 \pm 0.98$ & $20.56 \pm 1.29$ & $5.04 \pm 0.21$ \\
\hline PA-PDMS-5 & $36.31 \pm 1.35$ & $28.46 \pm 1.82$ & $30.57 \pm 1.24$ & $23.97 \pm 0.98$ & $5.35 \pm 0.25$ \\
\hline PA-PDMS-10 & $37.62 \pm 0.97$ & $30.93 \pm 1.34$ & $31.47 \pm 1.11$ & $25.89 \pm 1.51$ & $5.78 \pm 0.23$ \\
\hline PA-PDMS-15 & $40.09 \pm 1.58$ & $33.34 \pm 1.26$ & $33.28 \pm 1.23$ & $27.00 \pm 1.37$ & $6.07 \pm 0.22$ \\
\hline PA-PDMS-20 & $43.41 \pm 1.46$ & $33.55 \pm 1.08$ & $35.33 \pm 1.16$ & $27.30 \pm 1.12$ & $6.25 \pm 0.23$ \\
\hline
\end{tabular}
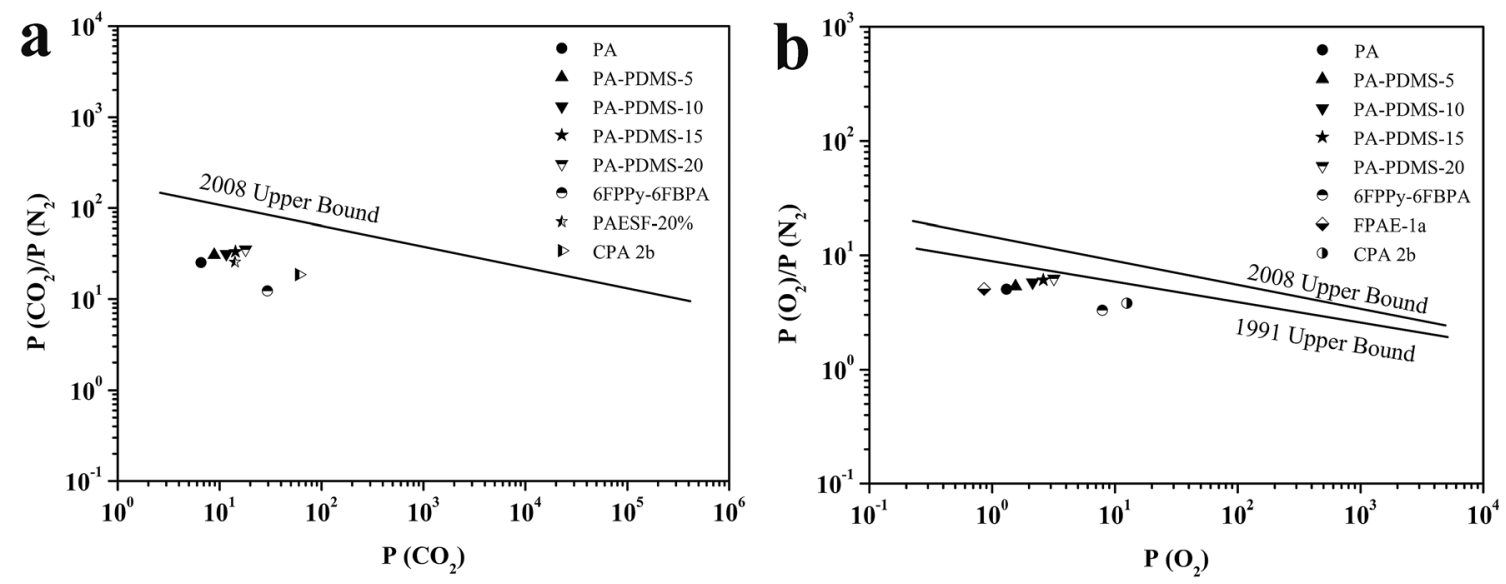

Fig. 4 Permeability selectivity trade-off map for (a) $\mathrm{CO}_{2} / \mathrm{N}_{2}$ separation and (b) $\mathrm{O}_{2} / \mathrm{N}_{2}$ separation.

polymer chains, and hence to a decrease of FFV values. Obviously, the order of $\lambda_{\max }$ values is opposite to that of FFV values.

\subsection{Effect of PDMS groups on gas permeability}

Permeation measurements were carried out using pure $\mathrm{H}_{2}, \mathrm{O}_{2}$, $\mathrm{CO}_{2}, \mathrm{~N}_{2}$ and $\mathrm{CH}_{4}$ at different pressures and temperatures. To investigate the effect of PDMS groups on gas permeability, a series of polyamide-poly(dimethylsiloxane)s containing PDMS groups were fabricated. The permeability of all gases

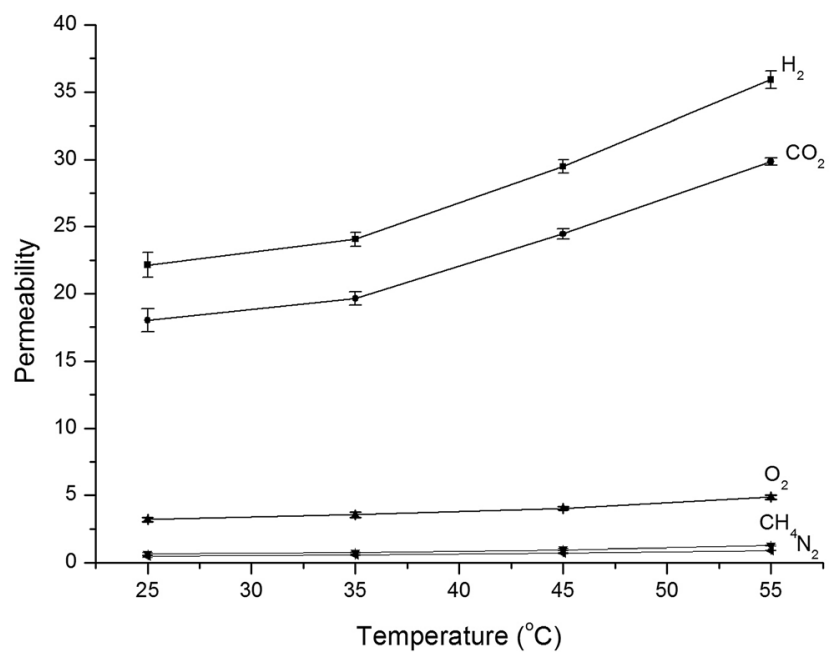

Fig. 5 Gas permeability of PA-PDMS-20 at different temperatures. at different PDMS contents is shown in Table 3. We can see that the gas permeability of the membrane increased with the increase of PDMS content, which is due to the high flexibility of -O-Si-O- bonds of PDMS. As the PDMS content increases from $5 \%$ to $20 \%$, an increase in the $\mathrm{CO}_{2}$ permeability was observed for the PA-PDMS- $x$ membranes. For instance, PA-PDMS-20 membrane exhibits a permeability of 18.02 barrer at $25^{\circ} \mathrm{C}$ and $1.0 \mathrm{~atm}$, which is much higher than that of PA-PDMS-5 membrane (8.87 barrer). A similar permeability behavior was observed for the rest gases $\left(\mathrm{H}_{2}\right.$, $\left.\mathrm{O}_{2}, \mathrm{~N}_{2}, \mathrm{CH}_{4}\right)$. The selectivity of PA-PDMS- $x$ membranes in relation to relevant gas-pairs is listed in Table 4. As shown in Table 4, the selectivity increases monotonously with increasing PDMS content. The PA-PDMS-20 membrane exhibits higher selectivity for the $\mathrm{CO}_{2} / \mathrm{N}_{2}$ (35.33) and $\mathrm{O}_{2} / \mathrm{N}_{2}$ (6.25) gas-pairs. This can be explained by kinetic diameter that the easier diffusion of $\mathrm{CO}_{2}$ and $\mathrm{O}_{2}$, due to their lower kinetic diameter $\left(\mathrm{H}_{2} 2.89 \AA \mathrm{CO}_{2} 3.3 \AA\right.$, $\mathrm{O}_{2} 3.46 \AA \mathrm{N}_{2} 3.64 \AA$,

Table 5 Permeation activation energy $\left(E_{\mathrm{P}}\right)$ of PA-PDMS-20 membrane

\begin{tabular}{llllll}
\hline & \multicolumn{5}{l}{$E_{\mathrm{P}}\left(\mathrm{kJ} \mathrm{mol}^{-1}\right)$} \\
\cline { 2 - 6 } Polymer & $\mathrm{CO}_{2}$ & $\mathrm{H}_{2}$ & $\mathrm{O}_{2}$ & $\mathrm{~N}_{2}$ & $\mathrm{CH}_{4}$ \\
\hline RPA-PPG (20\%) & 11.29 & 13.37 & 13.99 & 16.31 & 17.97
\end{tabular}




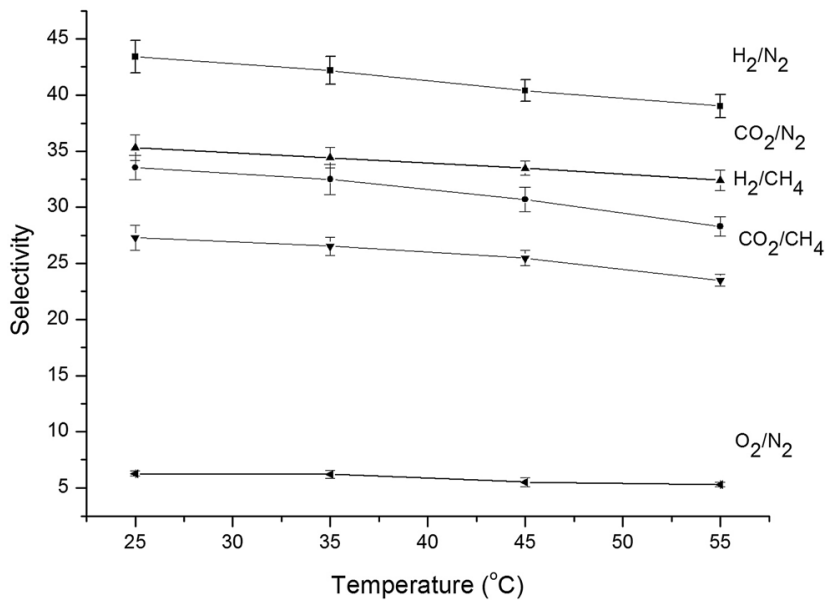

Fig. 6 Gas selectivity of PA-PDMS-20 at different temperatures.

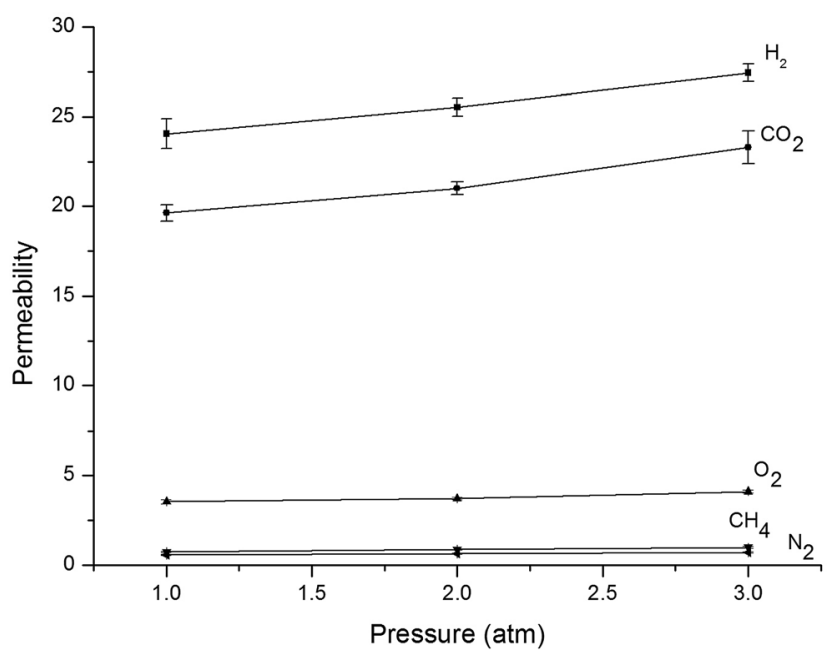

Fig. 7 Gas permeability of PA-PDMS-20 at different pressures.

and $\mathrm{CH}_{4} 3.8 \AA$ ). The permselectivity for the relevant gas pairs, $\mathrm{CO}_{2} / \mathrm{N}_{2}$ and $\mathrm{O}_{2} / \mathrm{N}_{2}$ versus $P\left(\mathrm{CO}_{2}\right)$ and $P\left(\mathrm{O}_{2}\right)$ of PA-PDMS$x$ membranes are plotted in the Robeson permeability/ selectivity trade-off plots, as shown in Fig. 4. The fabricated PA-PDMS- $x$ membranes exhibited very promising results, for $\mathrm{CO}_{2} / \mathrm{N}_{2}$ gas pairs, the data point of PA-PDMS-20 was close to the Robeson line in 2008 and for $\mathrm{O}_{2} / \mathrm{N}_{2}$ gas pairs which was close to the Robeson line in $1991 .^{27-30}$

\subsection{Effect of operating temperature}

The temperature dependence of gas permeability and selectivity of PA-PDMS-20 was investigated in the temperature range of 25$55{ }^{\circ} \mathrm{C}$ at a constant pressure of 1.0 atm. The PA-PDMS-20 membrane was selected for further investigation, since it exhibited the best separation performance. The corresponding results are presented in Fig. 5. As shown in Fig. 5, the permeability of PA-PDMS-20 gradually increased with the increase of operating temperature. For instance, the $\mathrm{CO}_{2}$ gas permeability has increased by $c a .40 \%$, i.e. from 18.02 to 29.83 barrer (Table 5). This results are in accordance to Arrhenius eqn (4):

$$
P=P_{0} \exp \left(\frac{-E_{\mathrm{P}}}{R T}\right)
$$

where $P$ is gas permeability coefficient; $P_{0}$ is the pre-exponential coefficients $R$ is $8.314 \mathrm{~J} \mathrm{~mol}^{-1} \mathrm{~K}^{-1} ; E_{\mathrm{P}}$ is the apparent activation energy for permeation process; and $T$ is the absolute temperature (K). The improvement in gas permeability was mainly attributed to the following reasons: (i) the thermodynamic energy of gas molecules is increased with temperature, resulted in an increase of jumping frequency; (ii) the mobility between polymer chains is increased with temperature increase, resulted to an increase of fractional free volume and molecules transport.

The selectivity of PA-PDMS-20 membrane gradually decreased with the increase of temperature as shown in Fig. 6. The permeation activation energy $\left(E_{\mathrm{P}}\right)$ of PA-PDMS-20 membrane for $\mathrm{H}_{2}, \mathrm{O}_{2}, \mathrm{CO}_{2}, \mathrm{CH}_{4}$ and $\mathrm{N}_{2}$ is shown in Table 5 . As illustrated in Table 5, the order of permeation activation energy was $E_{\mathrm{P}}\left(\mathrm{CO}_{2}\right)<E_{\mathrm{P}}\left(\mathrm{H}_{2}\right)<E_{\mathrm{P}}\left(\mathrm{O}_{2}\right)<E_{\mathrm{P}}\left(\mathrm{N}_{2}\right)<E_{\mathrm{P}}\left(\mathrm{CH}_{4}\right)$. This order is exactly opposite to the permeability coefficient: $P\left(\mathrm{CO}_{2}\right)>$ $P\left(\mathrm{H}_{2}\right)>P\left(\mathrm{O}_{2}\right)>P\left(\mathrm{~N}_{2}\right)>P\left(\mathrm{CH}_{4}\right)$. Gas penetrant with higher permeation activation energy led to an enhanced permeability with the increase in operating temperature, which in turn resulted in a decreased selectivity. ${ }^{31}$

\subsection{Effect of operating pressure}

The impact of pressure was assessed by employing $\mathrm{H}_{2}, \mathrm{O}_{2}, \mathrm{CO}_{2}$, $\mathrm{CH}_{4}$, and $\mathrm{N}_{2}$ at $35{ }^{\circ} \mathrm{C}$ in a pressure range of 1.0-3.0 atm [Fig. 7]. It is evident that the permeability of all gases $\left(\mathrm{H}_{2}, \mathrm{O}_{2}, \mathrm{CO}_{2}, \mathrm{CH}_{4}\right.$, $\mathrm{N}_{2}$ ) increases with pressure. This phenomenon was observed for glassy materials at high pressure, where the contribution of the Langmuir region to the overall permeability diminishes and gas permeability approaches a constant value associated with simple dissolution (Henry's law) transport. ${ }^{32}$ Koros and Paul suggested the immobilization theory for the correlation between

Table 6 The effects of pressure on diffusivity coefficient and solubility coefficient of PA-PDMS-20

\begin{tabular}{|c|c|c|c|c|c|c|c|c|c|c|}
\hline \multirow[b]{2}{*}{ Pressure (atm) } & \multicolumn{5}{|c|}{ Diffusion coefficient $^{a}$} & \multicolumn{5}{|c|}{ Solubility coefficient ${ }^{b}$} \\
\hline & $\mathrm{H}_{2}$ & $\mathrm{CO}_{2}$ & $\mathrm{O}_{2}$ & $\mathrm{CH}_{4}$ & $\mathrm{~N}_{2}$ & $\mathrm{H}_{2}$ & $\mathrm{CO}_{2}$ & $\mathrm{O}_{2}$ & $\mathrm{CH}_{4}$ & $\mathrm{~N}_{2}$ \\
\hline 2.0 & 7.66 & 5.37 & 2.27 & 0.39 & 0.31 & 3.72 & 4.62 & 1.88 & 2.23 & 2.03 \\
\hline 3.0 & 9.19 & 6.69 & 2.85 & 0.45 & 0.36 & 3.68 & 4.38 & 1.72 & 2.20 & 1.94 \\
\hline
\end{tabular}

${ }^{a}$ Diffusivity coefficient, $10^{8} \mathrm{~cm}^{2} \mathrm{~s}^{-1} \cdot{ }^{b}$ Solubility coefficient, $10^{3} \mathrm{~cm}^{3} \mathrm{STP} \mathrm{cm}^{-3} \mathrm{cmHg}^{-1}$. 


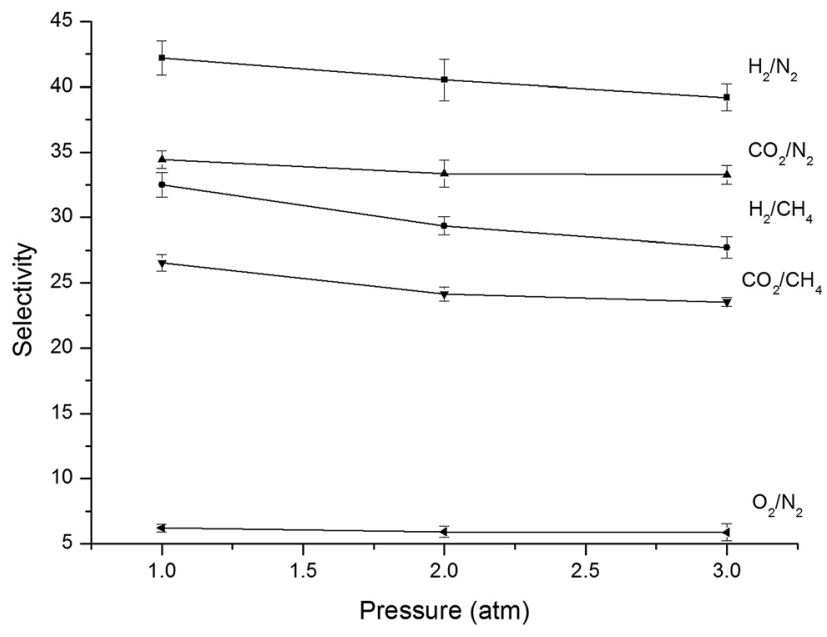

Fig. 8 Gas selectivity of PA-PDMS-20 at different pressures.

pressure and solubility and diffusivity coefficients. This model indicates in general that the $\mathrm{CO}_{2}$ and $\mathrm{CH}_{4}$ diffusivity coefficients increased with pressure whereas their solubility coefficients decreased upon increasing pressure. ${ }^{33,34}$ The diffusion coefficients at different pressures obtained in the present work are shown in Table 6. As shown in Fig. 7 and Table 6, the $\mathrm{N}_{2}$ and $\mathrm{CO}_{2}$ permeability of PA-PDMS-20 membrane increased by about 11.4 and $33.0 \%$, respectively, by increasing the pressure from 1.0 to $3.0 \mathrm{~atm}$. On the other hand, the diffusion coefficient declined by about $38.7 \%$ and $25 \%$ for $\mathrm{CO}_{2}$ and $\mathrm{N}_{2}$, respectively, by increasing the pressure from 1.0 to $3.0 \mathrm{~atm}$. A similar behaviour was observed for the rest gases. Fig. 8 shows the effect of pressure on ideal selectivity at $35{ }^{\circ} \mathrm{C}$, which is increased upon pressure increase. This is because gas penetrants with smaller diameter offer higher permeability upon pressure increase, which consequently leads to a higher selectivity.

\section{Conclusions}

In summary, a series of copolymers with different PDMS content were synthesized though polycondensation reaction. The chemical structure of PA-PDMSs was characterized by FTIR and ${ }^{1} \mathrm{H}$ NMR. The gas permeability of PA-PDMSs was investigated in a wide temperature and pressure range. $\mathrm{CO}_{2}$ permeability gradually increased upon increasing operating temperature and PDMS content, while $\mathrm{CO}_{2} / \mathrm{N}_{2}$ selectivity progressively decreased. The best performance was obtained for PA-PDMS-20, which showed the highest selectivity $\left(\mathrm{CO}_{2} / \mathrm{N}_{2}=\right.$ 41.84 and $\left.\mathrm{O}_{2} / \mathrm{N}_{2}=7.01\right)$ at $35{ }^{\circ} \mathrm{C}$ and $3 \mathrm{~atm}$, accompanied by $\mathrm{CO}_{2}$ and $\mathrm{O}_{2}$ permeability values as high as 29.29 and 4.91 barrer, respectively.

\section{Conflicts of interest}

There are no conflicts to declare.

\section{References}

1 P. D. E. Bernardo and G. Golemme, Ind. Eng. Chem. Res., 2009, 48, 4638.

2 D. L. Gin and R. D. Noble, Science, 2011, 332, 674.

3 A. Mondal and B. Mandal, J. Membr. Sci., 2014, 460, 126.

4 M. Carta, M. Croad, R. Malpass-Evans, J. C. Jansen, P. Bernardo, G. Clarizia, K. Friess, M. Lan and N. B. McKeown, Adv. Mater., 2014, 26, 3526.

5 J. R. Wiegand, Z. P. Smith, Q. Liu, C. T. Patterson, B. D. Freeman and R. Guo, J. Mater. Chem. A, 2014, 2, 13309. 6 P. M. Budd and N. B. McKeown, Polym. Chem., 2010, 1, 63.

7 A. Álvaro, M. Ramírez-Santos, B. Bozorg, V. Addis, C. Piccialli and E. F. Castel, J. Membr. Sci., 2018, 566, 346.

8 Z. Y. He, R. H. Yuan, Y. Zhang, W. D. Wang, J. F. Gao, C. H. Chen, H. Wu, X. J. Liu and Z. L. Zhan, Ind. Eng. Chem. Res., 2017, 56, 14604.

9 C. L. Zhang, L. X. Fu, Z. K. Tian, B. Cao and P. Li, J. Membr. Sci., 2018, 556, 277.

10 X. L. Ding, F. F. Tan, H. Y. Zhao, M. M. Hua, M. X. Wang, Q. P. Xin and Y. Z. Zhang, J. Membr. Sci., 2019, 570, 53.

11 A. Awad and I. H. Aljundi, Korean J. Chem. Eng., 2018, 35, 1700.

12 X. H. Ma, Z. K. Yao, Z. Yang, H. Guo, Z. L. Xu and C. Y. Y. Tang, Environ. Sci. Technol. Lett., 2018, 5, 123.

13 B. Parthasarathi, B. Debaditya and B. Susanta, Sep. Purif. Technol., 2013, 104, 138.

14 T. Y. Zhu, X. Yang, X. Q. He, Y. Y. Zheng and J. J. Luo, High Perform. Polym., 2018, 30, 821.

15 L. S. G. José, M. P. F. José, I. L. B. María and A. V. Manuel, Des. Monomers Polym., 2015, 18, 350.

16 R. Sulub-Sulub, M. I. Loría-Bastarrachea, H. Vázquez-Torres, J. L. Santiago-García and M. Aguilar-Vega, J. Membr. Sci., 2018, 563, 134.

17 X. Yang, T. Y. Zhu, Z. X. Xu, H. Q. Shan and J. J. Luo, React. Funct. Polym., 2018, 124, 48.

18 H. You, I. Hossaina and T. H. Kim, RSC Adv., 2018, 8, 1328.

19 N. Biolley, M. Gregoire, T. Pascal and B. Sillicn, Polymer, 1991, 32, 3256.

20 S. J. Luo, K. A. Stevens, J. S. Park, J. Moon, Q. Liu, B. D. Freeman and R. L. Guo, ACS Appl. Mater. Interfaces, 2016, 8, 2306.

21 I. Kammakakam, S. Nam and T. H. Kim, RSC Adv., 2016, 6, 31083.

22 D. F. Sanders, Z. P. Smith, R. L. Guo, L. M. Robeson, J. E. McGrath, D. R. Paul and B. D. Freeman, Polymer, 2013, 54, 4729.

23 S. Bisoi, A. K. Mandal, V. Padmanabhan and S. Banerjee, J. Membr. Sci., 2017, 522, 77.

24 J. J. Luo, T. Y. Zhu, Y. H. Song and Z. Q. Si, Polymer, 2017, 127, 52 .

25 M. G. Garca, J. Marchese and N. A. Ochoa, J. Appl. Polym. Sci., 2017, 134, 4682.

26 H. Masatoshi, K. Masakatsu, M. Itaru and Y. Rikio, Eur. Polym. J., 1989, 25, 349. 
27 Z. K. Xu, C. Dannenberg, J. Springer, U. Banerjee and G. Maier, J. Membr. Sci., 2002, 205, 23.

28 J. J. Luo, R. Q. Guo, M. Zhang and J. P. Li, High Perform. Polym., 2016, 28, 1005.

29 I. M. Tkachenko, N. A. Belov, Y. V. Yakovlev, P. V. Vakuliuk, O. V. Shekera, Y. P. Yampolskii and V. V. Shevchenko, Mater. Chem. Phys., 2016, 183, 279.

30 J. L. Santiago-Garciaa, J. M. Pérez-Franciscoa, M. G. Zolotukhinb, H. Vázquez-Torresc, M. Aguilar-Vegaa and M. O. González-Díaz, J. Membr. Sci., 2017, 522, 333.
31 S. Wang, Y. Liu, S. Huang, H. Wu, Y. Li, Z. Tian and Z. Jiang, J. Membr. Sci., 2014, 460, 62.

32 M. M. Khan, V. Filiz, G. Bengtson, S. Shishatskiy, M. M. Rahman, J. Lillepaerg and V. Abetz, J. Membr. Sci., 2013, 436, 109.

33 R. Xing and H. W. S. Winston, J. Taiwan Inst. Chem. Eng., 2009, 40, 654.

34 W. J. Koros, D. R. Paul and A. A. Rocha, J. Polym. Sci., Part B: Polym. Phys., 1976, 14, 687. 